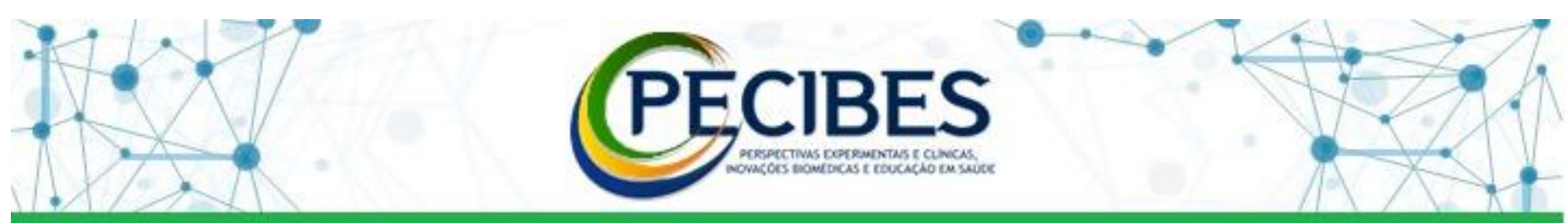

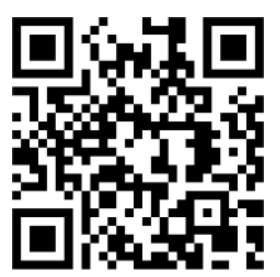

http://www.seer.ufms.br/i ndex.php/pecibes/index

\author{
* Autor \\ correspondente: \\ Higor Alexandre \\ Alves de \\ Oliveira, \\ Universidade \\ Federal do Mato \\ Grosso do \\ Sul - UFMS. E-mail \\ do \\ autor: \\ higor_oliveira@ufm \\ s.br
}

Key-words:

Aesthetic

sport, physical

profile,

interval training,

body

mass

Descriptores:

Deporte

estético, perfil físico,

entrenamiento

intervalado, masa

corporal.

\section{Composição corporal de atletas de ginástica artística feminina após 2 semanas de treinamento intervalado de sprint modificado}

Body composition of female artistic gymnastics athletes after 2 weeks of intervaled training of modified sprint

Higor Alexandre Alves de Oliveira' ${ }^{1}$, Juliana Fernandes Junqueira ${ }^{2}$, Zadriane Gasparetto $^{2}$, Sarita de Mendonça Bacciotti ${ }^{4}$

1. Profissional de Educação Fìsica, Mestrando no Programa de Pós-Graduação em Ciências do Movimento (PPGCMov), Instituto Integrado de Saúde (INISA), Universidade Federal de Mato Grosso do Sul (UFMS)

2. Profissional de Educação Fìsica, Mestranda no Programa de Pós-Graduação em Ciências do Movimento (PPGCMov), Instituto Integrado de Saúde (INISA), Universidade Federal de Mato Grosso do Sul (UFMS)

3. Profissional de Educação Fìsica, Doutora em Ciências do Desporto, Docente da Faculdade de Educação (FAED), Universidade Federal de Mato Grosso do Sul (UFMS)

INTRODUÇÃO: Os praticantes de ginástica artística (GA) aprimoram suas capacidades físicas desde a iniciação, buscando melhora no desempenho. Há evidências científicas de mudanças na composição corporal após a utilização de alguns métodos, dentre eles, o Treinamento Intervalado de "Sprint" modificado (mSIT), porém ainda não testado em ginastas. O mSIT é definido como um exercício que envolve a alternância de curtos períodos de alta intensidade menor do que 10 segundos e em períodos de baixa intensidade para sua recuperação, sendo considerado um método eficiente para o desenvolvimento da saúde e desempenho, refletindo na composição corporal. OBJETIVO: Analisar as alterações na composição corporal após realização do treinamento mSIT de atletas de GA feminina do Centro de Formação de Atletas de Campo Grande - MS (CEFAT), em novembro de 2021. MÉTODO: O estudo de caráter experimental, com intervenção de 2 semanas, aprovado pelo Comitê de Ética da UFMS, parecer $n^{\circ}$ 5.086.867, de 08/11/2021, foi realizado com 8 ginastas do sexo feminino $(11,49 \pm 1,40$ anos) com altura de 146,66 $\pm 6,64 \mathrm{~cm}$, foi utilizado estadiômetro portátil, balança digital e analisador de bioimpedância (ImbodyS10). RESULTADOS: Foram apresentados de forma descritiva, utilizando média e desvio padrão. Para comparação de valores médios pré e pós intervenção foi utilizado o teste t de Student de medidas repetidas no programa Jamovi e o nível de significância adotado foi de $5 \%$. Os valores pré e pós intervenção, respectivamente, foram $7,21 \mathrm{~kg} \pm 6,26$ e $37,13 \mathrm{~kg} \pm 6,31(\mathrm{t}=0,464)$ para o peso corporal, $13,69 \% \pm 6,61$ e $14,63 \% \pm 6,65(\mathrm{t}=-2,165)$ para o percentual de gordura e $17,21 \pm 2,45 \mathrm{~kg}$ e $16,79 \pm 2,89 \mathrm{~kg}(\mathrm{t}=1,339)$ para massa de gordura. A análise inferencial apresentou valores maiores $p>0,05$, não havendo diferenças estatísticas significativas entre os períodos pré e pós intervenção. CONCLUSÃO: A manutenção de valores pré e pós intervenção nesta amostra pode estar relacionado com aspectos do treinamento e a falta de controle da ingesta alimentar. 